\title{
Cuando la razón práctica no es tan pura (Aportaciones e implicaciones de la hermenéutica feminista alemana actual: a propósito de Kant)
}

\author{
LUISA POSADA KUBISSA \\ Instituto de Investigaciones Feministas
}

Este trabajo se asoma a la filosofia kantiana sobre los géneros, que, inscrita en el ámbito práctico de la razón, confiere "carta de naturaleza" a la desigualdad entre hombres ("sujeto») y mujeres («objeto» del discurso de ese "sujeto").

Desde la hermenéutica feminista alemana se viene poniendo de relieve cómo el pensamiento kantiano en este punto entra en conflicto con sus propias tesis ilustradas y universalizadoras. Pero estas posiciones hermeneuticas actuales. han vuelto su mirada crítica hacia las tesis que hoy apuestan por la diferencia genérica y han encontrado en ellas un curioso «aire de familia» con el esencia- lismo kantiano; a este aspecto presta el presente artículo particular interés.

$Y$ ello porque, como se apunta en las siete conclusiones aquí propuestas, no parecen infundados los reparos hermenéuticos de las pensadoras alemanas: un ferninismo, que quiere transitar por la vía de la diferencia esencial entre los sexosigéneros, puede encontrarse explorando (y explotando) caminos que otros pensadores anteriores ya recorrieran; $y$, lo que es más, se trata de pensadoras que, como en el caso de Kant, no cabe considerar particularmente proclives al feminismo, ni tampoco parecen, por otro lado, puntales a reivindicar para los intereses del mismo.

\section{A modo de introducción}

Si partimos del supuesto de que la dualidad teórica se convierte, en la filosofía de Kant, en desigualdad práctica a la hora de aplicarla a la reflexión sobre los sexos, comprenderemos que, de tal premisa, se desprenden "barbaridades» teóricas, tales como que las mujeres no serán nunca, ni podrán serlo, sujetos de deber (y de derecho), ni tampoco poseer, desde la lógica kantiana, conciencia ética, en el sentido del imperativo categórico de Kant. Pero admitir estas consecuencias, tan poco acordes con un talante ilustrado como el de Kant, nos lleva, no sólo a temerarias afirmaciones del más marcado sesgo misógino, sino incluso a afrontar una argumentación, que retrocede a etapas históricamente anteriores al siglo XVIII y se inscribe en la órbita del más puro y descarnado sexismo tribal. En el Kant de la razón práctica se impone el norte de un deber tan elevado, que justifica, no ya el incumplimiento, sino el pisoteo incluso de todo derecho del otro de sí / del otro genérico. Tal deber superior, presentado como sinterés 
de la humanidad", le permite apartarse, sin mala conciencia, del terreno de la racionalidad al considerar la dualidad de los sexos. Se trata, para Kant, del "Deber" con mayúsculas.

Avalado por la más antigua tradición cultural que, en pro del orden natural y universal de las cosas, obliga a "poner al otro en su sitio" - tanto para saberse "lo uno", como para saberse a costa de "lo otro" de sí-, avalado por esta tradición de re-creador del cosmos, digo, Kant escribe y piensa sobre las mujeres. Y lo hace guiado, no ya por las conquistas de sus facultades a la sola luz de la razón, es decir, no por un uso crítico y desprejuiciado de sus aptitudes racionales, sino más bien con un tono poco atemperado y una actitud intolerante. En el estado de naturaleza, «la mujer es un animal doméstico», asevera Kant sin miramientos. ${ }^{1}$

Kant sitúa la razón práctica a la cabeza de todo su sistema filosófi$\operatorname{co}^{2} \mathrm{y}$, con ello, el tema de las relaciones entre los sexos adquiere una dimensión importante, puesto que se inserta justamente en ese ámbito práctico de la razón pura. Ahora bien, sería exacto decir que en Kant, cuando se trata de disertar sobre las diferencias entre los sexos -cosa que, por cierto, admite con toda tranquilidad-, habla primordialmente el "corazón" (por no señalar otras partes menos académicas), y no la razón. Tanto en sus Observaciones sobre el sentimiento de lo bello y lo sublime, de $1764,{ }^{3}$ como en la Antropologia desde el punto de vista pragmático, ya de $1798,{ }^{4}$ este tema antropológico se trata desde el terreno, plagado de prejuicios e, incluso, de desprecio, que corresponde menos a la condición de intelectual esclarecido y más a la del hornbre que coincide aquí en todo con sus congéneres menos ilustrados. Podría decirse que, en Kant, la razón teórica no tiene fundamento fuera de la razón práctica; $\mathrm{e}$, incluso, que ni siquiera cabe hablar de razón misma sin esta última -con lo cual, dicho sea de paso, puede ponerse en entredicho, desde tal perspectiva, el supuesto formalismo ético en Kant, y mostrar cómo la razón, precisamente en virtud de la hegemonía práctica, será siempre, y ante todo, razón interesada-.

En el terreno de la dualidad sexual por resumirlo de una manera un tanto jocosa, Kant, cuando hay que defender los privilegios genéricos, se lanza al ruedo y lleva el combate teórico-práctico aquí hasta el final: por tanto, tiene que descabellar toda posible amenaza contra la desigualdad establecida en la relación con "el otro" (sexo) y, partiendo de la existencia de tal relación, desechar, vía argumentación universalizadora, cualquier reclamación en sentido igualitario.

Kant ironiza sobre la posibilidad de que las mujeres se equiparen a los hombres en el ámbito académico e intelectual: «En lo que respecta a las mujeres cultivadas", apunta Kant, entrando ya en faena, "éstas necesitan sus libros tanto como su reloj; a saber: lo llevan para que se vea que lo 
tienen, aun cuando esté parado o no esté puesto en hora con relación al soln. ${ }^{5}$ Para aderezar esta opinión, ya de por sí jugosa, Kant amplía su registro de improperios: «Una mujer letrada que tenga la cabeza llena de griego, como la Señora Dacier, o que sostenga profundas discusiones sobre mecánica, como la Marquesa de Chatelet, tendría además que tener barba; porque así se expresaría mejor la imagen de pensadoras sesudas, por la que luchann.6

Cabe también mencionar aquella otra teoría de Kant, por la cual la relación -estética y natural- entre «lo bello» y slo sublime» pasa a convertirse en el arquetipo de relación entre los dos sexos, siendo, por supuesto, la categoría de «sublimes la que corresponde al sexo masculino, que tiene por tanto, un entendimiento y unas virtudes igualmente superiores. Esta deducción, aparentemente cándida, de Kant enmascara, sin embargo, una despiadada voluntad de "descolgar" a todo el género femenino del proceso de ilustración, excluyéndolo del ámbito de la cultura y del conocimiento que, Kant lo sabe como buen ilustrado que es, puede significar el resorte más directo para la puesta en cuestión del papel de exclusión/reclusión adjudicado a las mujeres en el reparto social. Como consecuencia inmediata de tal perversidad, Kant concluye por conceder a las mujeres el beneficio de apartarlas de la piedra filosofal y del saber, carga pesada que debe quedar en las más fuertes manos de los varones: "[la mujer] no aprenderá, por tanto, geometría; acerca del principio de razón suficiente o de las mónadas sólo sabrá lo mínimo imprescindible [...]. Las bellas pueden dejar a Cartesius (Descartes) girando en su torbellino, sin inmutarse siquiera porque Fontenelle quiera hacerles companía bajo las estrellas; y su atractivo nada pierde porque ignoren lo que Algenotti se esforzó por describir acerca de la fuerza de atracción de la materia, siguiendo a Newton. En cuanto a la historia, no se llenarán la cabeza con batallas; y, en lo referente a la geografía, tampoco lo harán con nombres de fortalezas, ya que es tan impropio de ellas oler a pólvora, como de los hombres oler a almizcle»?

Ante un panorama tan desolador y a la vista de esa pedagogía «avanzada" que Kant propone para las mujeres, se siente la tentación inmediata de elaborar una relación de frases o sentencias kantianas que podrían conformar un modelo perfecto de catálogo de injurias. Leyendo a Kant, y sin necesidad de una exégesis profunda de sus textos, es tan imposible no toparse con alguna muestra como las aquí citadas, que una se pregunta si los muchos y muchos intérpretes de Kant que en el mundo han sido, olvidaron apuntar esta cuestión; o si, lo que es más probable, compartían hasta tal punto sus tesis sobre las mujeres, que no percibieron el oscurantismo filosófico del gran pensador de las luces en este punto.

Ahora bien, dado que la reacción inmediata de llevar estos papeles 
kantianos al juzgado de guardia más próximo se ve también inmediatamente refrenada por el sentido común, y ante la perspectiva de caer en el desdichado papel de amanuense, transcribiendo sin más los muchos disparates que Kant repite en este terreno, y que no necesitan de comentarios, pues hablan por sí solos, es preferible optar por una estrategia que puede resultar menos directa, pero, pienso, mucho más eficaz: la de atender, no tanto a las afirmaciones del propio Kant sin más, sino más bien a las de las miradas críticas que, a su vez, miran a aquéllas y lo hacen, además, desde una perspectiva feminista. En general, puede decirse que se trata de pasar revista a algunas posiciones teóricas, que coinciden en cuanto a considerar insostenible el discurso kantiano sobre los sexos y que, más que de-construirlo, lo que quieren es definitivamente derrumbarlo. Porque ese discurso encierra el prejuicio que ha guiado la historia y, por tanto, pasarlo por alto significa ocultar una parte importante de ese proceso histórico. Y, por otro lado, porque también desde estas opciones hermenéuticas se ha comprendido que, por un ladrillo mal puesto (en este caso, toda una viga madre), sí puede caerse la casa entera. En general, los pensadores suelen «hacer la vista gorda» cuando se les apunta este aspecto misógino de la filosofia kantiana, disculpando la falta por el genio. Pues bien, algunas pensadoras han revisado esa pequeña falta del travieso filosofo prusiano y se han encontrado con una pieza clave de su pensamiento; clave porque, junto con otras piezas de la razón práctica, apuntala el resto del edificio kantiano; y clave, también, porque constituye un peligro real para las mujeres, en tanto reproduce e, incluso, en algunos aspectos, ahonda su relación de desigualdad con el sexo masculino, ungiendo además esta desigualdad como ley de la naturaleza misma.

\section{Algunas posiciones actuales en la hermenéutica feminista alemana (a propósito de Kant)}

Si nos atenemos al panorama hermenéutico ferninista del país en el que vivimos, antes de viajar a Alemania, encontramos ya importantes muestras de lo que Paul Ricoeur llamó "Filosofía de la sospecha», aplicada a Kant (calificativo este, que, por cierto, tanto o más que a Marx, Nietzsche o Freud, le cuadra al pensamiento feminista, en cuanto pensamiento crítico y desenmascarador). ${ }^{8}$ También entre nosotros más que usospechar", se "sabe" a ciencia cierta que los postulados kantianos, en el terreno de la filosofía sobre los sexos, no están guiados por los puros y transparentes intereses racionales, sino que, en el fondo de los mismos, hierve la más práctica $\multimap$, incluso, pragmática - voluntad de "no apearse del carro" (en este caso, hay que apuntar en Kant una actitud éticoracional aquí totalmente interesada, en nada asimilable a un imperativo 
categórico supuestamente formal, y por ello mismo, universal). El razonamiento que late tras esta cuestión parece del tipo de «si tengo muchos iguales, tocaré a menos en el reparto», sentencia que, indudablemente, tiene todo el aspecto de ser una máxima moral hipotética, nada categórica y, por cierto, de miras no muy elevadas. Cabe plantearse cómo puede un ilustrado de pro anteponer, hasta tal punto, sus intereses patriarcales a las exigencias de su propia ilustración. Ni que decir tiene que, seguramente, a Kant le costó más reconocer que la metafísica está fuera del campo de la ciencia, lo que la propia razón establece en su autorrevisión $-\mathrm{y}$, con ello, designarla como "producto bastardo [...] de la razón"que excluir a las mujeres del campo de los sujetos, moral y racionalmente autónomos e iguales a los sujetos-varones de su misma especie. Sin duda actúa Kant en este sentido, y como ya se ha indicado, dentro de una lógica de intereses, que cabe describir así: «Decir que nuestros quereres son morales, mero deber ser contra el ser que existe, incontaminados por el poder o la esperanza de detentarlo, es ingenuidad o hipocresía". ${ }^{10}$ No cabe duda de que difícilmente podría tildarse al gran crítico ilustrado de ingenuo; y, concretamente en su reflexión sobre el género femenino, se mantiene alejado de la lógica del disimulo o las hipócritas afirmaciones encubiertas. Abiertamente opina, al contrario, que "El género femenino es insensible a todo lo que sea deber u obligación. Ellas hacen algo sólo porque quieren, y el arte consiste en hacer que quieran sólo lo que es bueno»."1

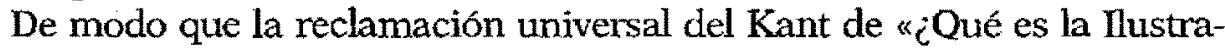
ción?" de 1784, en el sentido de emancipar a la razón humana de todo sometimiento, yugo o sumisión a cualquier otro tutor heterónomo a la razón misma, hay que entenderlo restringido al ámbito de los seres racionales de sexo masculino, pues, para las mujeres, seguirán siendo necesarios los tutores que las guíen en su minoría de edad y, de hecho, tales tutores, para el caso de su contacto con el conocimiento, no habrán de ser otros que sus propios maridos. ${ }^{12}$ Con lo cual, no sólo se recorta sustancialmente la pretendida universalidad en la filosofía ilustrada de Kant -lo que Ángeles Jiménez Perona señala como «quiebra» o "fisura» de la universalidad en Kant-, sino que, como ya es patente a estas alturas, excluye a las mujeres del ámbito ético, niega su actuación por el deber y, a la vista de la función esencial que el ámbito práctico-moral juega para el sistema de la razón mismo, las convierte en una ubella» irracionalidad, cuya única vía de participación en los elevados fines de la humanidad emancipada por la razón pasa por su sometimiento al entendimiento y la virtud «sublimes» del sexo masculino. ${ }^{13}$

Lo que Ursula Nolte, en su reflexión sobre Kant, considera un mero desajuste intelectual sin más, ${ }^{14}$ era ya interpretado en 1953, con menos esfuerzo teórico pero mayor contundencia, como simple y pura misoginia 
por Buytendik. ${ }^{15}$ Otras posturas hermenéuticas más matizadas encuentran la clave del pensamiento kantiano sobre los sexos en una actitud ambivalente, que, por un lado, participa del modelo de pensamiento modernoburgués - por cuanto entiende el matrimonio como pacto-m, mientras que, por otro lado, presenta rasgos pre-ilustrados y pre-burgueses cuando se refiere al contenido de ese contrato. Así, para Kant, en el fondo del contractualismo conyugal subyace la lucha entre los sexos y no el vínculo amoroso que caracteriza la comprensión moderno-burguesa del matrimonio. 16

Se trate de una misoginia pre-ilustrada y ancestral en Kant, o del cruce entre dos concepciones históricas en transición, el hecho es que, para este filósofo, ambos sexos se hallan tajantemente separados. Y la relación entre ambos no se ajusta al modelo de lo diferente dentro de la igualdad, sino que claramente parte de la diversidad desigualitaria. Amén del carácter esencialista de tal división (con lo cual cabría hablar de una "misoginia de la diferencia» aquí), las soluciones kantianas para reencontrar el terreno de la unidad posible entre los sexos no dejan de ser igualmente tradicionales, es decir, tan antiguas como la propia razón sin ilustrar. La primera solución de unidad de lo desigual (del sexo femenino con el masculino, por tanto), pasa por «la pareja unida [que] configura una sola persona moral $» .^{17}$ Aquí se habla del matrimonio como encuentro entre el entendimiento del hombre y la sensibilidad o «el gusto" de la mujer (por cierto, uno de tantos temas parejos a la filosofía teórica de la dualidad en Kant: dualidad de facultades [sensibilidad-entendimiento], la dualidad imaginación-entendimiento, la de fenómeno-noúmeno, etc.). Pero, antes de "echar las campanas al vuelo» y celebrar aquí el tratamiento kantiano del tema, que hace de los sexos una misma unidad o totalidad dividida simplemente en dos partes - tal y como se congratula Nolte en su artículo-, hay que apuntar que cse terreno común de la diversidad genérica, que Kant sitúa en el matrimonio, esa unidad (Einheit) de la diversidad (Verschiedenheit) no implica indiferenciación y, mucho menos, igualdad, por cuanto esa "persona moral" puede romperse si uno y otro sexo no mantienen sus diferencias (Unterschiedlichkeiten), que, además, lo son por el mismo orden natural de las cosas. ${ }^{18}$ Hay que decir que, por otro lado, la unidad sólo es posible por la reducción de un extremo al otro (en este caso, del "sexo bello» o femenino al "sublime» o masculino, al modo como, en la razón teórica, la unidad sólo es posible por el sometimiento de una facultad, la sensibilidad, a otra, el entendimiento). Así, pues, esta primera solución a la dualidad/desigualdad entre los sexos no se salda, desde luego, en Kant por el lado de la igualación entre ellos (por mal que le pese a Nolte $y$, como veremos, en ciertos aspectos también a Jauch).

La segunda posibilidad de unidad de lo diverso (de los sexos, en este 
caso) reaparece en la "Antropología desde el punto de vista pragmático» años más tarde. Aquí Kant plantea la unidad de los caracteres de ambos sexos como necesidad inscrita en el propio orden de la naturaleza, de modo tal que esa unidad se convierte ahora en orientación teleológica del orden natural mismo. Si la mujer es la depositaria de la fertilidad, arguye Kant, será también el sexo más débil; y, de ahí, su requerimiento del sexo más fuerte para protegerla. Así, las relaciones entre los sexos pueden encontrar un terreno de unidad, siguiendo la fórmula kantiana, según la cual la mujer "manda", pero el hombre "reinas. ${ }^{19}$ De forma que el sexo fuerte está llamado a ejercer una función racional, en tanto que el «bello sexo» sólo obedece a una inclinación ciega (recordemos aquí la relación que se establece en la razón en su dimensión teórica entre intuición y concepto: si la primera es necesaria para que el concepto no esté vacío de contenido, el segundo es el que realmente guía a la intuición, ya que, según la conocida sentencia kantiana, la intuición sin concepto es "ciega»).

Ahora es el momento de atender a las posiciones y opiniones que el pensamiento kantiano sobre los géneros ha merecido por parte de las interpretaciones actuales, hechas desde la óptica del feminismo (alemán, en particular). En principio cabe señalar que, desde luego, no todas ellas comparten el optimismo hermenéutico ya apuntado de Ursula Nolte. Así, Genevieve Lloyd escribe en 1985: «Paradójicamente, la kantiana concepción de la moral, que acentúa los aspectos universales y comunes a todo espíritu humano, proyecta en las ideas modernas la imagen de un desarrollo moral inferior en las mujeres. El contraste kantiano entre la tendencia pura y la universalidad supra-personal del deber reaparece, por ejemplo, en Freud, en su conocida opinión de que el desarrollo moral de las mujeres va muy por detrás del de la conciencia moral plena de los hombres». ${ }^{20}$ Sin embargo, esta desigualdad explícita en cuanto al grado de conciencia moral entre hombres y mujeres para Kant ha sido interpretada también desde claves menos enconadas por Ursula Pia Jauch, quien encuentra que tal diferencia podría resumirse en «Der Mann ist, die Frau soll werden» ( $E$ El hombre es, la mujer debe llegar a ser»); y deduce, de tal fórmula, un atisbo alentador en Kant: según Jauch, esto implica que su antropología acepta un posible potencial de transformación de la condición femenina - al menos, en lo que respecta al ámbito moral-; con lo cual, cabe plantearse que la diferencia entre ambos sexos no es inmutable y rígida, sino susceptible de modificación, si bien, apunta Jauch, sigue en pie el pequeño problema de si la mujer es sujeto o tan sólo objeto de dicha virtual transformación de su grado de ser moral. ${ }^{21}$ Bien mirado, el problema que, según Jauch, cabe plantearse no sería, con mucho, un problema secundario. Y lo que ella apunta a modo de interrogante, parece más bien una cuestión claramente respondida, 
incluso desde las tesis de la propia Jauch. Efectivamente, si, como ella misma apunta hasta la saciedad en su ensayo, la antropología kantiana (y, concretamente, la Antropología desde el punto de vista pragmático) tiende a reconocer como objeto de estudio más al sexo femenino que al masculino, tal y como el propio Kant afirma, ${ }^{22}$ entonces está claro que la mujer se convierte para Kant en un punto de análisis antropológico que, por su misma tematización, tiene por fuerza poco de sujeto de conocimiento y deviene, antes bien, objeto de tal. Pero, que se sepa hasta la fecha, pocos objetos de conocimiento han tenido la capacidad de transformarse a sí mismos y es más bien el sujeto que los conoce quien los delimita, los define y establece los márgenes de su transformación, al menos epistemológicamente. La propia Jauch resume esta apreciación en otra reflexión sobre la antropología kantiana, señalando cómo "el discurso sobre la virtud del siglo XvII es esencialmente esto: un enorme intento de someter el ser femenino al catálogo de virtudes femeninas establecido según los criterios éticos masculinos". ${ }^{23}$ Un tercer escrito de la propia Pia Jauch —en el contexto de un debate en torno a los problemas éticos de la tecnología genética actual-, nos da indirectamente la clave del interés kantiano por el estudio del sexo femenino tan celebrado por esta misma autora. ${ }^{24}$ Aquí se maneja la idea de que el supuesto mejoramiento de la especie subyace en el fondo de técnicas genéticas dudosamente morales. Pues bien, no otra cosa parece guiar a Kant cuando, en sus apreciaciones antropológicas, incluso en las que corresponden al legado póstumo de su obra, sostiene la necesidad de interesarse por el sexo femenino, ya que, no siendo éste sustancialmente importante per se, sí lo es en la medida en la que "[...] hombres y mujeres conforman una totalidad moral».25 De modo que, siguiendo con Nolte, parece que sí llevaría razón al afirmar que la óptica kantiana abre la puerta a la comprensión unitaria del género humano. Ahora bien, como ya se ha indicado aquí, la unidad no deviene sin desigualdad y la polaridad sexual parece mantenerse aun dentro de ese todo, que precisa, además, para darse de la reducción de un polo a otro. Dicho en otras palabras, lo que a estas intérpretes les parece esperanzador - la idea de totalidad y unidad que aparece en la antropología kantiana-, bien puede leerse desde una comprensión menos alborozada; a saber: que Kant defiende la diferencia esencial entre los sexos, aun cuando, como buen ilustrado, proponga a la vez la superación de lo que es "por naturaleza" por lo que podría ser "por razón». $Y$, de ese modo, si bien habla de unidad para la diversidad sexual, lo hace por la vía de la necesidad racional, con lo cual no concede a las mujeres carta de igualdad alguna con respecto de los hombres, ni siquiera por el mero hecho de pertenecer a la especie racional; $y_{\text {, }}$ por otro lado, si la unidad ha de devenir "contra natura» será siempre guiada por aquellos que, naturalmente, son superiores $\mathrm{y}$, además, se hará 
con los costes y sacrificios que tal artificio exija: sin traspasar los límites esencialmente diferenciadores y por vía de sometimiento del «sexo bello» (mujeres) al «sublime» (hombres).

Cuando Geneviève Fraisse se pregunta en un artículo breve por los fundamentos de la diferencia entre los sexos, ${ }^{26}$ vuelve a afirmar, como ya hiciera en su libro, ${ }^{27}$ que las tesis y teorías sobre tal diferencia sexual se hallan tan desperdigadas a lo largo de la historia del pensamiento que no cabe adscribirlas a unos textos, autores o épocas determinadas. Tal afirmación no puede sorprendernos, ni tampoco su consecuencia inmediata, en el sentido de reclamar la necesidad de una reconstrucción retrospectiva. Lo que sí sorprende es que esta circunstancia pueda convertirse en un criterio metodológico, entendido como que, para cada muestra histórica de discriminación o trato desigualitario del sexo femenino, se busque una explicación coyuntural y distinta que dé razón de esta óptica patriarcal; y que de ahí se desprenda que tal reconstrucción se contrapone a otra manera diversa, epistemológicamente ahistórica, de considerar el tema, planteado así como cuestión de raíz ontológica. Así, en el caso de Fraisse misma, el paso del feudalismo a la democracia burguesa y sus consecuencias inmediatas parece deslizarse por el contexto histórico-explicativo, a modo de categoría de explicación de diversas concepciones vistas, así, para sentencia, en tanto que productos del proceso políticoinstitucional, y pendientes de un análisis ulterior que, más allá de éste, se ejercería sobre la diferencia de los sexos en sí, abstraída de la historia del problema. Pero, volviendo al tema y al personaje «invitado», hay que apuntar que estas tesis no explican la semejanza entre textos dispares, tanto en cuanto a la época como en cuanto al pelaje de sus autores; baste recordar, en este sentido, el ejemplo ya citado con anterioridad, que conecta estrechamente - $-y$ casi literalmente - a Kant con Freud, en lo que hace a la inmadurez moral de las mujeres respecto de la de los varones. También cabe argüir aquí investigaciones que, como en el caso de Cornelia Klinger, parten del supuesto, diverso al de Fraisse, según el cual una rápida ojeada a esos dispersos retazos teóricos sobre la desigualdad entre los sexos nos ofrece la más compacta visión de una historia del pensar que, si bien discontinuamente, se ha mantenido dentro de la óptica de la razón patriarcal y, con ello, dentro de la más clara tradición que busca legitimar teóricamente esos intereses prácticos. ${ }^{28}$ Con esto no se está pretendiendo defender aquí simplezas tales como que el sistema político que históricamente predomine no determine las diversas formas de la dominación -en este caso, referida a la condición femenina-; pero sí que los intereses patriarcales —de la razón y de la acciónvinculan todas estas formas entre sí y las hacen partícipes de un mismo fenómeno, que va más allá de la praxis política concreta sin por ello moverse fuera de ésta, en una esfera pretendidamente trascendente o 
"en sí», apartada de la propia historicidad. No partir de esta última premisa equivaldría a no adscribir una tarea a la hermenéutica feminista, ya que, como Cornelia Klinger apunta, sólo puede acometerse una tarea de "de-construcción" cuando se acepta que hay algo enteramente construido, y no meramente fragmentado, a través de la historia como es, en este caso, el discurso "del pensamiento masculino", 29 que no es otro que el de la razón patriarcal.

Retomando el tema de la dualidad/totalidad en la concepción de los géneros, hay que repetir, una vez más, que la alegria de Nolte o Jauch ante la visión kantiana del tema, no parece muy justificada. Si hay interpretaciones que hacen recaer los males de la desigualdad de las mujeres durante la Ilustración en la transición del feudalismo al orden moderno-burgués, habrá que concluir forzosamente que el medievo y el feudalismo supusieron tiempos mejores para lo femenino. ${ }^{30}$ Sin embargo, hay que recordar que ya santo Tomás de Aquino, por no poner un ejemplo venial, había hablado en el siglo XIII de la completud del género masculino, contraponiéndola a la deficiencia del femenino, al que, por tal motivo, podía calificársele de "hombre imperfecto». ${ }^{31} \mathrm{E}$ incluso, si entramos aún más en el fondo en el túnel del tiempo, encontramos datos de esta relegación de las mujeres desde el año 3000 a.C., tal y como indica el estudio, ya clásico, de Elfriede Walesca Tielsch. ${ }^{32}$

Por lo tanto, pues, no cabe otra posibilidad hermenéutica que hacer a Kant partícipe de unos prejuicios tan ancestrales casi como la propia razón en el tema de los sexos, y, de hecho, mucho más antiguos que la Ilustración. A la vista de los textos, difícilmente puede interpretarse en claves conceptuales más sofisticadas lo que Kant explicita en términos, más que evidentes, groseros: "Lo que el género femenino tiene es más impulso y corazón que carácter. Es sorprendente cómo el sexo femenino es totalmente indiferente al bien común; el que, aun cuando no sean insensibles hacia las personas particulares que conocen, sí lo sean en lo que toca a la noción del todo, que no tiene para ellas ninguna fuerza; en tanto esto no sea comprendido, lo cual favorece su natural inclinación, asisten al curso de los acontecimientos sin inmutarse. No fueron hechas para echar una mano en la obra común, y piensan que es absurdo ocuparse de algo más que de su propio provecho. Esto está bien así. Porque los varones pueden recuperarse con ellas de sus cuitas públicas.. ${ }^{33}$ Pocos comentarios caben a esta "profunda» reflexión kantiana. Quizá merezca la pena recordar que, para esta función de "reposo del guerrero», que Kant parece adjudicar a las mujeres aquí, pocas alforjas teóricas hacian falta. Efectivamente, Kant refleja y repite una opinión comúnmente extendida, y que, ni que decir tiene, encuentra su sustento teórico en la premisa de la esencial diferencia entre los sexos. Una rápida mirada hacia la literatura y el ensayo de la época, sugerida por el artículo de Marion Beaujean, ${ }^{34}$ nos ofrece de in- 
mediato el retrato de esta condición femenina en calidad de refugio reparador del luchador varón: "Cuando fuera en el mundo truena, cuando todos los ánimos y fuerzas luchan entre sí, cuando soplan los vientos de guerra y todas las esperanzas en un tiempo mejor se desvanecen, cuando incluso los más fuertes y valerosos se desaniman, qué otra cosa le queda al hombre que el trato confiado con su felicidad doméstica, su íntima complacencia ante una noble esposa, con su cariñosa y silenciosa bondad $[\ldots . .] \times$.

Plenamente acorde con esta lírica formulación, la filosofía de Kant sobre los sexos no sólo excluye a las mujeres de toda universalidad de especie, sino que las recluye en el ámbito de lo doméstico y privado, donde han de servir de solaz para su fatigado marido $y$, de paso, aliviarle de todo otro cuidado que pueda entorpecer su dedicación infatigable a la vida pública. ${ }^{36} \mathrm{El}$ gran drama de esta idea no está sólo en la exclusión de las mujeres de la vida pública y de los derechos/deberes de todo ciudadano, sino también en que tal exclusión se realiza mediante la reclusión que - y no es sólo el caso de Kant- está sancionada por los grandes pensadores de la libertad, enemigos acérrimos de toda forma de esclavitud. $^{37}$

Desde la óptica de la diferencia sexual que legitima la ausencia de las mujeres del ámbito de la historia y el quehacer humanos, al menos en lo que toca a su participación en él, habría que entrar en algunas observaciones que, si bien implican a Kant en tanto que pensador de la diferencia, van más allá de él y conectan directamente con la otra cara de esta reflexión: es decir, con lo que hace a la hermenéutica feminista actual. Y esto, además, porque no podría darse por cumplida esta rápida mirada a la hermenéutica feminista que se ocupa del pensamiento kantiano, concretamente desde la órbita cultural alemana, pasando por alto la crítica que, al hilo de la Ilustración y, en particular, de Kant, se despliega en dicha hermenéutica hacia posiciones teóricas actuales que, desde el feminismo, apuestan por las tesis de la diferencia.

Cuando una de las voces más representativas de este pensamiento de la diferencia inicia uno de sus textos claves con la afirmación de que tal diferencia sexual es, por así decirlo, "el tema de nuestro tiempo", 38 parece inevitable recordar, en el sentido de Jauch, cómo Kant, llevado del mismo énfasis, subrayaba que «[...] en la antropología, la singularidad femenina constituye un estudio para los filósofos, en mayor medida que la masculinas. ${ }^{39}$ Curiosa coincidencia ésta, por cuanto sitúa el tema de la diferencia sexual como centro en épocas tan diversas, por un lado, $y$, por otro, en tanto que presupone, para ambos casos, la premisa de que tal diferencia existe de manera esencial; lo que, volviendo a Cornelia Klinger, se ha definido como la característica de toda filosofía de la dua- 
lidad genérica, a saber: la ontologización de los géneros a partir de la diferencia puramente biológica o genital. ${ }^{40}$ Bien es verdad que, si vamos algo más a ciertos sustentos filosóficos de las tesis de Irigaray y nos adentramos, tan sólo un poco, en la espesa tundra de la filosofía, o filosofías, de la deconstrucción, encontramos también semejanzas curiosas entre algunas observaciones de Kant y otras de estas filosofías. Así, ambas posiciones parecen coincidir en lo que hace a la vinculación que se establece entre las mujeres y algo así como "el buen gusto" o «el estilo", con las diferencias terminológicas propias de cada una de estas perspectivas. Kant entiende, en su Antropología desde el punto de vista pragmáti$c o$, que la finalidad de la naturaleza al formar el carácter femenino es, además de la de reproducir la especie, reproducir también el buen gusto y, así, refinar a la sociedad. Qué otra idea cabe intuir latiendo en la airada argumentación de Derrida, cuando exclama literalmente: «El hombre cree en la verdad-mujer. Y las ferninistas, contra las que Nietzsche multiplicó todo su sarcasmo, son en realidad hombres. El movimiento feminista es el procedimiento por el cual la mujer desea asemejarse al hombre, al filósofo dogmático, en tanto que reclama la verdad, la ciencia, la objetividad, es decir, en tanto que, conjuntamente con la colectiva ilusión humana, a la que se adhiere, reclama también el efecto de castración. El movimiento feminista quiere la castración - también la de la mujer. Ha perdido el estilo», ${ }_{4}^{4}$

Parece que Derrida quiere llevar su rigor deconstructivo hasta el límite de reconvenir al movimiento feminista por carente de "buen gusto». Si por tal entendemos la categoría que Kant, entre otros, adjudicó a la naturaleza femenina, está claro que al filósofo de la crítica de-constructora no le debió de parecer, ya en 1976, una categoría a de-construir, sino más bien a preservar; o bien, lo que seguramente es más acertado, no le pareció un constructo logocéntrico (ni androcéntrico, en este caso), con lo cual sigue inmerso en la valoración del mismo como característica esencial y natural del sexo femenino. $Y$ aunque ni se pretende, ni se podría entrar aquí en el proceloso océano del pensamiento de la de-construcción, ni siquiera en su parcela derridiana, sí parece urgente apelar al buen sentido (antes que al buen gusto) de las feministas de la diferencia, que se tengan por tales, para que reconsideren sus alianzas teóricas y epistemológicas, pues la cosa en Derrida está clara en la cita reseñada: o feministas, o de la diferencia, ésta es aquí la cuestión hamletiana y no parece haber otra opción posible.

En otro orden de cosas, la hermenéutica de la diferencia reclama la deconstrucción del discurso androcéntrico que, por mor de una economía típicamente masculina, se despliega en torno a constantes polaridades: materia/forma, dios/hombre, naturaleza/cultura, sujeto/objeto, etc.; sobre esa lógica binaria, Irigaray apunta que su disposición es una 
necesidad interna del propio discurso, como discurso constituyente de la subjetividad, sin que, fuera de él, exista en la realidad una dualidad tal. Así señala, por ejemplo, que si no se diera esa «mujer» externa al discurso masculino, no existiría el wombre" dentro de dicho discurso que le constituye en cuanto sujeto. ${ }^{42}$ Independientemente de las resonancias que hay en esta argumentación de la filosofía del idealismo alemán (vía Hegel), al aplicar esa crítica de-constructiva a nuestro pensador prusiano - al que, contra lo que pudiera parecer, todavía no hemos olvidado resulta que las condiciones a priori de la sensibilidad, establecidas por Kant, responden también a ese modelo binario y, por tanto, a un pensamiento, cuya actitud logocéntrica hay que socavar. Por ello, en una de las (pocas) ocasiones, en las que Irigaray se ocupa de la Crítica de la Razón Pura, de manera explícita, afirma: «El tiempo pasa a ser territorio interior del sujeto mismo; el espacio, territorio externo [...] El sujeto, en cuanto señor del tiempo, se convierte en el trazo central que ordena el mundo, acompanado por la exaltación de su instante y de su eternidad: dios. Él activa la transición entre tiempo y espacio. ¿Es acaso esto lo que se invierte en la diferencia sexual? Ahí lo femenino es vivido como espacio, a menudo, sin embargo, con sus connotaciones de barranco o de noche (¿en tanto que el espacio de dios es claridad?), y lo masculino como tiempo. Una transformación histórica exige una acepción y una concepción transformadas de Espacio/Tiempos. ${ }^{43}$ Al hilo de este (y otros) textos, cabe pensar que la hermenéutica feminista de la diferencia conllevaría, no sólo una nueva ética, sino incluso una nueva conceptualización de los términos que, tradicionalmente, han sido sustanciales en la historia del pensamiento e, incluso, en la propia dinámica de configuración de la subjetividad. No se trataría, por tanto, de apropiarse ni de participar del discurso de la razón en su decurso histórico, sino que, más bien, parece convocarse aquí a la construcción de un tipo de racionalidad y un discurrír diferentes. Aun no entrando aquí a fondo en la obra de Irigaray, sí se puede señalar que, al menos en lo que toca a la critica de la filosofía kantiana, no aparecen por ninguna parte las nuevas conceptualizaciones de esa dualidad espacio/liempo que el texto parece prometer en las páginas dedicadas a dicha crítica. ${ }^{44}$ Probablemente es esta ausencia de concreción de las propuestas de Irigaray lo que hace concluir a Alexandra Busch, una de sus detractoras alemanas: "Se habla de una revolución del pensar y de la ética, con concepciones totalmente nuevas, y con relaciones absolutamente transformadas e, incluso, revolucionarias entre los seres humanos y el mundo, entre los seres humanos y dios, de los seres humanos entre sí. Con ello, sin embargo, Irigaray promete a las lectoras mucho más de lo que finalmente pueden obtener. Porque cuando se mira más detenidamente, [...] las aparentemente nuevas re- 
laciones y concepciones son, como mucho, variantes hasta ahora descuidadas de pensamientos pre-existentes [...]. Porque también en el centro del modelo de mundo de Irigaray se mantiene la pareja heterosexual. En el centro de todas las reflexiones acerca de la sexualidad gravita la fecundidad [...]. Lo masculino y lo femenino, categorías centrales de esta "nueva" historia, permanecen atadas a la anatomía: la mujer sigue siendo ante todo mujer-madre, toda posible productividad de lo femenino queda ligada a la genitalidad femenina».45 En la misma línea crítica, que rechaza el eterno-femenino, divinizado y mitificado en el pensamiento de Irigaray, Astrid Deuter-Mankowsky, desde una posición más cercana a esta autora francesa, incide en señalar que "Irigaray compara la diferencia sexual con la diferencia ontológica. Si la primera, a su vez, pasa a ser ontológica, es algo que dejo aquí de lado en la discusión. Pero, en cualquier caso, Irigaray va tan lejos, que se permite, partiendo de la diferencia entre los cuerpos masculinos y femeninos, establecer también un deseo diferente para uno y otro sexo, y concluir que a ambos corresponderían sistemas simbólico-representativos igualmente específicos». ${ }^{46} \mathrm{Si}$ damos un paso más en el panorama del rechazo hermenéutico alemán al feminismo de la diferencia nos encontramos con pensadoras que, de la mano teórica de Seyla Benhabib, ${ }^{47}$ retoman abiertamente la oposición de esta línea de pensamiento a toda pretensión feminista de una moral específicamente femenina, pretensión representada en particular por Carol Gilligan y extendida en Alemania a partir de su traducción en 1984.48

En concreto, a partir de la crítica de Benhabib a las propuestas de Gilligan en la obra citada, Heidemarie Bennet-Vahle o Andrea Maihofer han elaborado recientemente fuertes contratesis hacia el pensamiento que, desde la invocación/reivindicación de la diferencia sexual, aboga por una nueva reelaboración de la teoría moral que, partiendo del dualismo esencialista, asume postulados de la antropología ilustrada (menos «ilustre») sobre los sexos y bordea el peligro de un biologicismo acrítico, poco innovador e, incluso, claramente anclado en el mito de lo femenino, tal y como éste ha sido tradicionalmente diseñado desde el pensamiento androcéntrico. $^{49}$ Para abandonar este quizá excesivo excursus sobre la hermenéutica feminista alemana, que aborda la confrontación con la hermenéutica (francesa en su origen) de la diferencia sexual, resumamos lo hasta ahora indicado en la voz de Elfiriede Walesca Tielsch, quien en el Congreso de la Asociación Internacional de Filósofas, en 1989, declaraba: «Aun cuando reconozcamos que ser mujer, ser hombre, o ser hermafrodita sólo tiene que ver con unos (pocos) genes, la biología no es un destino, sino que recibe su gran o su pequeña significación de la cultura [...]. Sólo sabemos que la mujer es esencialmente persona, como lo es el hombre, por su mismo destino biológico y que está atada al género o sexo sólo mínima- 
mente (y, por ello, no puede ser explicada sólo como ser sexual y tratada sólo como tal, ni siquiera como andro-gina)».50

\section{A modo de conclusiones}

Cuenta el propio Kant que Diógenes, al acometer la lectura de la última página de un texto algo aburrido, intentó reavivar el interés de sus oyentes exclamando: "Coraje, caballeros, vislumbro tierra!".51 Esta misma apelación a la indulgencia del lector impone ahora que las conclusiones que se extraigan - siempre con ánimo de provisionalidad y nunca dándolas por definitivas- sean lo más concisas posible. Ello obliga necesariamente a resumir, quizá algo apresuradamente, algunos aspectos tratados aquí, y otros que de aquéllos se derivan, con lo que todo resumen tiene de simplificación, por un lado, y también de alivio, por otro. Así, pues, se tratará ahora de «ir al grano»:

1. Sin duda, la antropología kantiana piensa a las mujeres "como un objeto de la razón práctica de los hombres».52

2. Tal tematización del sexo femenino por parte de la razón interesada - y, concretamente, patriarcal- de los hombres se realiza por el sometimiento de facto de las mujeres, por su reclusión al ámbito de lo privado y su correspondiente exclusión del de lo público, negándoles su participación en la dominación racional, científica y política del mundo.

3. Esta óptica desigualitaria, presente también en las reflexiones kantianas sobre los sexos, no puede justificarse como lógico producto del contexto histórico, en el que tales reflexiones se insertan. Los contraejemplos de pensadores, igualmente implicados en ese contexto y que, pese a ello, pensaron sobre las mujeres desde visiones más igualitarias, desmienten este extremo. ${ }^{53}$

4. A partir de este esencialismo genérico de Kant -0 , si se prefiere, de su defensa de la diferencia esencial de los sexos-, este pensador justifica como ley de naturaleza el predominio de un sexo (el «sublime», esto es, el suyo) sobre el otro (el «bello»), apuntando que tal predominio responde, además, al más alto deber del interés común. ${ }^{54}$ De modo que, como señala Carol Pateman, Kant no ve contradicción alguna entre el dominio del pater familias y la idea de igualdad, evocada en la concepción contractual de las relaciones conyugales. Aun cuando Kant, como sigue apostillando Pateman, defiende el derecho de autodeterminación de todo individuo, que ningún contrato puede conculcar y que sólo puede serlo por la fuerza, esta «ley de autonomía» sufre un severo recorte, una excepción en lo que hace al papel de las mujeres en el contrato de matrimonio. Aquí, evidentemente, el filósofo parte, concluye Pateman, de la premisa de que las mujeres, a causa de su natural disposición, nunca pueden alcanzar el pleno estatus de ciudadanas de derecho. .5 
5. De suyo, puede resumirse, por lo dicho, la antropología $-y$ también la ética-- kantiana como una filosofía de la diferencia, que, además, sitúa tal diferencia, en el caso de los sexos, en el terreno de la desigualdad práctica para las mujeres. Pero, yendo algo más allá, parece claro que, al menos en el terreno de las éticas abstractas, "Nuestra relación con el otro está determinada por las normas de la igualdad formal y de la reciprocidad: cada uno tiene derecho a esperar y tomar de nosotros lo que nosotros podemos esperar y tomar de él", en palabras de Seyla Benhabib. 56 De ahí, y llevándolo al terreno concreto de las Observaciones... kantianas, Benhabib deduce que tales requisitos de igualdad (al menos formal) y de reciprocidad (siempre práctica) son incumplidos en la teoría moral de Kant; es el caso, por ejemplo, de su concepción de la «bella virtud", la de las mujeres, que, hecha de "compasión" y "piedad", queda subrogada y por debajo de la "auténtica virtud" del varón, guiada ésta por principios fundamentales. .7

6. De lo dicho se deriva que difícilmente podría ser igualitario, y ni siquiera por ello mismo moral, un pensamiento que parta de la tajante desigualdad, formal y práctica, entre los extremos genéricos. De ahí que las críticas a la hermenéutica de la diferencia, asociadas en particular a su proyecto ético (con Carol Gilligan) y a su vocación ontologizadora (en particular, con Luce Irigaray) se multipliquen en autoras de la órbita alemana, dedicadas al estudio de la llustración y/o, en particular, al pensamiento de Kant. Entre algunas de éstas, aquí recogidas (Cornelia Klinger, Alexandra Busch, Heidemarie Bennet-Vahle, Andrea Maihofer, Elfriede Walesca Tielsch...), parece cundir la sospecha, si no la certeza, de que el discurso de la diferencia, más que deconstruir el edificio racional andro/ogocéntrico, no hace sino repetirlo desde nuevas tonadillas. En este sentido, es sintomático que una de las aproximaciones críticas más exhaustivas a "La ética de la diferencia sexual» de Luce Irigaray, la realizada por Alexandra Busch, concluya su análisis con el siguiente epígrafe: «3. Resumen: una vieja canción -entonada de nueva manera»; e, incluso, ya sin freno alguno en su indignación hermenéutica, inicie este último apartado transcribiendo literalmente la letra de la inolvidable canción de la película Casablanca (la que comienza con "You must remember this / a kiss is still a kiss / etc. $).{ }^{58}$

7. Pero, en definitiva, si esta reflexión se ha hecho eco de las críticas al feminismo de la diferencia desde algunos de los planteamientos del feminismo hermenéutico alemán de la actualidad, ha sido porque este último enlaza directamente sus críticas al pensamiento actual de la diferencia con su investigación, igualmente crítica, de la filosofía kantiana sobre los sexos. Que se llegue a cuestionar la hermenéutica defensora de la diferencia, tan en boga actualmente, vía Kant, o a la inversa, nos parece aquí, no sólo interesante, sino, además, lógico. Porque, por aca- 
bar de una vez y hacerlo a modo de acertijo, ¿a quién cabría atribuir las palabras que siguen?: "El acto de conocimiento se complica notablemente por el hecho de que el sujeto de conocimiento no es uno, sino dos». No parece aquí mediar mucho camino entre Kant y quienes firman este texto, que no son otras que las mujeres de la Libreria delle Donne di Milano..$^{59}$

Queda abierta la puerta a la discusión acerca de las implicaciones, teóricas y también práctico-políticas, que las tesis de la diferencia conllevan. En concreto, la propuesta política de las italianas citadas se vertebra en torno a tres puntos: no aceptar la igualdad formal que la ley procura; no considerar a las mujeres un grupo social homogeneo y sometido, sino un género distinto con múltiples intereses; y no participar en las estructuras simbólico-políticas creadas por los hombres para reglar sus propias relaciones y conflictos. ${ }^{60}$ Sin duda se trata de posiciones de facturación atractiva, al menos tanto como estas otras palabras: "No neguéis a la razón lo que hace que ella sea el bien supremo sobre la tierra; a saber: el privilegio de ser la piedra de toque para toda verdad [...]. Hay ciudadanos que se erigen en tutores de los otros y, en lugar de dar argumentos, intentan [...] desterrar toda investigación racional [...], por medio de prejuicios formulados como dogmas obligatorios $[\ldots]{ }^{6}, 61$

\section{NOTAS}

1. I. Kant: Antropologie in pragmatischer Hinsicht [Antropología desde el punto de visto pragmático] (ed. Weischedel), XI, Francfort, Suhrkamp, 19824, p. 841; AK., VII, 1907. También hay edición en Reclarn, ed. por W. Becker (epil. de Hans Ebeling), Stuttgart, Reclams Universal-Bibliothek 7541 (4), 1966-1968.

2. Si nos atenemos a la interpretación, entre otros, de J. Villacañas-Berlanga: La formación de la Crtica de ta Razón Pura, Valencia, Universidad de Valencia, Dep. de Historia de la Filosofia, 1980 .

3. I. Kant: Beobachtungen über das Gefüh des Schönen und Erhabenen [Observaciones sobre el sentimiento de to bello y lo sublime] (ed. Weischedel), II, Francfort, Suhrkamp, 19824; AK, II, 1912.

4. Cf. Anthropologie...

5. I. Kant: Beobachtungen,..., p. 847.

6. Ibid., p. 852 .

7. Ibid. pp. 852-853.

8. Véase, en este sentido, la alusión de Amelia Valcárcel en Sexo y filosofía. Sobre "mujer» y "poder», Barcelona, Anthropos, 1991, p. 107.

9. En términos de Celia Amorós: Hacia una crítica de la razón patriarcal, Barcelona, Anthropos, 1985, p. 101.

10. A. Valcárcel: op. cit., pp. 99-100.

11. I. Kant: Beobachtungen ..., p. 854.

12. Ibid, pp. 864-865.

13. Ibid, pp. 850 y ss. 
14. U. Nolte: «Frauenbild und Frauenbildung in der Geschlechterphilosophie Kants», Zeitschrift für Pädagogik, año 9 (1963), pp. 346*362,

15. Buytendik, Die Frat Natur-Erscheinung-Sein, Colonia, 1953, p. 64.

16. Interpretación que hace, en particular, Barbara Duden, en «Das schöne Eigentum. Zur Herausbildung des bürgelichen Fraueribildes an der Wende vom 18. zum 19. Jahrhundertw, Kursbuch (Francfort), 47 (1977), pp. 125-140.

17. I. Kant: Beobachtungen..., p. 867.

18. Ibid, p. 868 .

19. I. Kant: Antropologie...

20. G. Lloyd: Das Patriarchat der Vemunft: 'männlich' und 'weiblich' in der westlichen Philosophie, Bielefeld, Daedalus Verlag, 1985, pp. 92-93.

21. U.P. Jauch: Immanuel Kant zur Geschlechterdifferenz. Aufklarische Vonarteilskritik und bürgerliche Geschlechtsvomundschaft, Viena, Passagen Verlag, 19892, p. 44.

22. bid, pp. 38, 48 y otras innumerables referencias a lo largo de la obra.

23. U.P. Jauch, «Männliches Sittengesetz-weibliche Sitz-Samkeit akute Reflexionen zu einem philosophischen Dauerbrenner", en 1789/1989. Die Revolution hat nicht stattgefunden, documentación del $\vee$ Congreso de la Asociación Internacional de Fílósofas (ed. A. DeuterMankowsky, A. Ramming y E.V. Tielsch), Tubinga, Edition Diskord, 1989.

24. Id: "Von der Nausea Ethica" (ed. U. Konnertz), Grenzen der Moral Ansätze feministischer Vernunftkritik, Tubinga, Edition Diskord, 1991.

25. I. Kant: Nachlass. Ver A. Stopczyk: Was Philosophen über Frazen denken, Munich, Mathes und Geitz Verlag, 1980, p. 62.

26. G. Fraisse: «Zwiefacher Verstand und die eine Natur. Grundlagen der geschlechterdifferenz", Die Philosophin. Tubinga, Edition Diskord, 2, 1990, pp. 7-16.

27. Id.: La musa de la razón. La democracia excluyente y la diferencia de los sexos (trad. A.H. Puleo), Madrid, Cátedra, 1991.

28. C. Klinger: "Das Bild der Frauen in der Philosophie und die Reflexion von Frauen auf die Philosophies, en K. Hauser y $\mathrm{H}$. Nowotny (comps.), Wie mönnilich ist Wissenschaft?, Francfort, Suhrkamp, 1986, pp. 62-84.

29. Ibid., p. 81 .

30. Esta es la tesis que, abiertamente, defiende Joan Kelly en " $i$ Tuvieron las mujeres un Renacimiento? $n$, en Historia y género: las mujeres en la Europa modema y contemporánea, Valencia, Alfons el Magnànim, 1990, pp. 93-126.

31. Santo Tomás: Summa Contra Gentiles, II, pp. 264, 270, 274, 334, etc., de la edición extractada de H. Fahsel, Zurich, 1949. Para una ampliación del tema de la visión sobre las mujeres en el pensamiento preilustrado e ilustrado alemán, véase Becker-Cantarino, B.: Der lange Weg zur Mündigkeit. Frauen tund Literatur in Deutschland von 1500 bis 1800 , Munich, Deutscher Taschenbuch Verlag, 1987.

32. E.W. Tielsch: «Die Philosophin. Geschichte und Ungeschichte ihres Bentisstandes seit der Antike», en H. Bendkowski y B. Weisshaupt (eds.), Was Philosophinen denken. Eine Dokumentation, Zurich, 1983, pp. 309-328; aqui, p. 315.

33. I. Kant: Nachlass. Ver A. Stopczky: op. cit., p. 128.

34. M. Beaujean: "Das Bild des Frauenzimmers im Roman des 18. Jahrhunderts", Wolfenbiutteler Studien zur Aufklärung (Wolfenbüttel), III (1969), pp. 2-24.

35. C. Pockel: Investigación sobre la relación entre lo agradable y to bueno, en Werke, II, Hannover, 1797-1802, p. 232.

36. En este aspecto, parece que las influencias de Rousseau sobre Kant, ya de por sf innumerables, se convierten en una especie de simbiosis teórica con él. Véase, en este sentido, Rosa Cobo Bedia: Democracia y patriarcado en Jean Jacques Rousseau (tesis doctoral por la Universidad Compluterse de Madrid, 1992), en particular, las conclusiones.

37. Aun cuando se salga un poco del tema, es recomendable, por interesante, el tratamiento que de esta reclusión femenina se hace, para el ámbito de la literatura, en la obra de Sandra Gilbert y Susan Gubar. The Madwoman in the Attic. The Woman Writer and the Nine- 
teenth Century Literary Imagination (New Haven. Yale University Press, 1979), donde la triada metafórica de aencierrohlocura/escape* se aplica al estudio, en particular, de las grandes novelas goticas, como Jane Eyre de Ch. Brontë.

38. L. Irigaray: Éthique de la différence sexuelle, París, 1984. Versión extractada al alemán en R. Grossmass y C. Schmere (eds.), Feministischer Komposs, patriarchales Gepäck, Francfort, Suhrkamp, 1989.

39. I. Kant: Antropologie... Véase todo el apartado dedicado a "El carácter del género».

40. C. Klinger: op cil., p. 79.

41. J. Derrida: "Sporen. Die Stile Nietzsches", en W. Hamacher (ed.), Nietzsche aus Frankreich, Francfort/Berlin, 1986. (Trad. cast.: Valencia, Pre-textos, 1981.)

42. L. Irigaray: op. cit, p. 16 de la versión alemana.

43. Ibid., p. 3.

44. Ibid., pp. 117-121.

45. A. Busch: aDie metaphorische Schleier des ewig Weiblichen-Zu Luces Irigaray's Ethik der sexuellen Differenz», en R. Grossmass y C. Schmere (eds.), op. cit, p. 169.

46. A. Deuter-Mankowsky: "Von neuen Welten und weiblichen Göttern», en Weiblichkeit in der Modeme, Tubinga, Edition Diskord, 1986, p. 65.

47. En particular, tras su traducción al alemán: Der verallgemeinerte und der konkrete Andere. Ansitze zu einer feministischen Moraltheorie en E. List y H. Studer (eds.), Denkverhältnisse, Feminismus und Kritik, Francfort, 1989.

48. C. Gilligan: Die andere Stimme. Lebenskonflikte und Moral der Frau, Munich, 1984.

49. En este sentido, véase $H$. Bennet-Vahle: "Die Differenz ist ausgeschlossen. Aktuelle Überlegungen zur Geschlechtphilosophie Kants», en U. Konnertz (ed.), op. cit., 1991. En el mismo sentido, también de la misma autora, véase "Über das moralische Anderssein der Frau: zur Carol Gilligans Entwurf einer weiblichen Ethik», en B. Gilles y B. Schinzel (eds.), Bei gleicher Qusalifikation.... Aachen, 1990, pp. 123-124. De Andrea Maihofer hay que referirse a "Ansätze zur Kritik des moralischen Universalismus. Zur moraltheoretischen Diskussion um Gilligans Thesen zu einer 'weibliche' Moralauffassung", Feministische Studien/Radikalität und Differenz (Francfort), año 6 (noviembre, 1988), pp. 32-53.

50. E. W. Tielsch: “Die Rolle der 'håuslichen Freiheit' bei der Demokratisierung von Ehe und Familie in eigenen Erfahrungshorizont der zeitgenössischen Philosophinnen-PhilosophenEhepaares", en Deuter-Mankowsky, Ramming y Tielsch (eds.), op. cil., pp. 19-37; aquí, p. 37, nota 17.

51. I. Kant: Träumes eines Geistersehers erläutet durch Träume der Metaphysik (ed. AK.), II, pp. 315-374 (ed. Weischedel), I, pp. 921-989, aquí p. 983. (Trad. cast de P. Chacón e I. Reguera: Los stueños de un visionario, Madrid, Alianza, 1987.)

52. En palabras de Lieselotte Steinbrügge: "Vernunftkritik und Weiblichkeit in der französischen Aufklärung", en Deuter-Mankowsky, Ramming y Tielsch (eds.), op. cit., pp. 65-79; aquí, p. 65 .

53. He ahi a Von Hippel, correctivo progresista de Kant en este aspecto, como señala Jauch en Immanuel Kont zur..., op. cit., pp. 203-224; incluso ya en 1673 el cartesiano Poullain de la Barre con su discurso "De l'égalité dè deux sexes..." (reimpr. en Paris, 1984); o la proclamación de Condorcet sobre el derecho de ciudadanía para las mujeres, fechado el 5 de julio de 1790 en el Joumal de la Société de 1789; o, yendo más allá, las consideraciones sobre el tema hechas por Stuart Mill.

54. I. Kant: Metaphysik der Sitten [Metafisica de las costumbres] [1797] (ed. Weischedel), VIII, Francfort, Suhrkamp, 1968-1982; AK, V, 1907, p. 279.

55. C. Pateman: The Sexual Contract, Cambridge/Oxford, 1988, p. 169; ver también hasta la p. 173 para este aspecto.

56. S. Benhabib: «Der verallgemeinerte und der konkrete Andere. Ansätze zu einer feministischen Moraltheorie», en E. List y H. Studer (eds.), op, cit., p. 468.

57. Ibid.

58. En A. Busch: op. cit., p. 168. 
59. Concretamente en su extracto de "Non credere di avere dei diritti...", editado en alemán, "Nicht glauben, Rechte zo haben. Wie weiblich Freiheit ensteht", de Laura Balestrini, Maria Grazia Campari y Traudel Sattler, en Deuter-Mankowsky, Ramming y Tielsch (eds.), op. cit., pp. 253-260, aqui p. 253. (Hay trad. castellana: No creas tener derechos, Madrid, Horas y horas, 1991.)

60. En una suerte de relación "homo-sexual" del género masculino, en palabras de las italianas citadas, p. 256.

61. I. Kant: Was heisst: sich im Denken orientieren? [1786], AK., VIII, 1911. (Trad. cast. de C. Correas: ¿Qué significa orientarse en el pensamiento?, Buenos Aires, Leviathan, 1982; aqui, pp. 61-62.) 